Growth of thick, crystalline material using dc-magnetron sputtering in Mag1 deposition chamber

S. Bajt, J. Alameda, S. Baker, J. S. Taylor

November 3, 2005 
This document was prepared as an account of work sponsored by an agency of the United States Government. Neither the United States Government nor the University of California nor any of their employees, makes any warranty, express or implied, or assumes any legal liability or responsibility for the accuracy, completeness, or usefulness of any information, apparatus, product, or process disclosed, or represents that its use would not infringe privately owned rights. Reference herein to any specific commercial product, process, or service by trade name, trademark, manufacturer, or otherwise, does not necessarily constitute or imply its endorsement, recommendation, or favoring by the United States Government or the University of California. The views and opinions of authors expressed herein do not necessarily state or reflect those of the United States Government or the University of California, and shall not be used for advertising or product endorsement purposes.

This work was performed under the auspices of the U.S. Department of Energy by University of California, Lawrence Livermore National Laboratory under Contract W-7405-Eng-48. 


\title{
Growth of thick, crystalline material using dc-magnetron sputtering in Mag 1 deposition chamber
}

\author{
Saša Bajt \\ November 2, 2005 \\ and \\ Jennifer Alameda, Sherry Baker and John S. Taylor
}

Summary: We demonstrated dense, non-columnar growth of thick Mo films by moving the substrates in and out of the plasma thus allowing the surface reconstruction and by interrupting the growth with Si layers. The multilayers made this way have very smooth surface, about 1.3 $\mathrm{nm}$ rms high spatial frequency roughness, while also maintaining the periodicity of a reflective coating. These preliminary results hint that the surface reconstruction is an important physical process that controls the growth mechanisms. Further studies, combined with theoretical modeling, are essential to further our knowledge on how to predict and control desired microstructure for different materials.

Objective: This is an attempt to determine if interruption in the growth of the crystalline material affects the overall density and microstructure of the coating. Such interruptions occur in deposition chambers with movable substrates or movable sources. This test was performed with molybdenum which has an amorphous-to-crystalline transition at around $2 \mathrm{~nm}^{1}$. The columnar growth of Mo was additionally suppressed with amorphous Si layers.

Experimental details: The deposition chamber has two dc-magnetron sputtering sources with sputtering up geometry. One sputtering gun was sputtering Mo and the other one Si. The following deposition parameters were used:

$\mathrm{P}_{\mathrm{Si}}=360 \mathrm{~W}$,

$\mathrm{P}_{\mathrm{Mo}}=340 \mathrm{~W}$

Ar pressure $=1$ mTorr,

Base pressure $=1.76 \times 10^{-7}$ Torr

A $100 \mathrm{~mm}$ diameter Si wafer substrate was mounted facing down and was constantly spinning around its axis. The substrate was mounted on a platter which rotates above the sources with computer controlled velocity profile. The power on the sources and the Ar pressure are constant during the run. The thickness of the individual layer is directly controlled with the velocity of the platter with the mounted substrate and the time that the substrate spends over a particular

\footnotetext{
${ }^{1}$ S. Bajt, D. G. Stearns, P. A. Kearney, "Investigation of the amorphous-to-crystalline transition in Mo/Si multilayers”, JAP 90, 1017-1025 (2001).
}

\section{University of California}


sputtering source. The sputtering sources are mounted 180 degrees apart thus allowing some surface reconstruction on the substrate between the deposition of Si and Mo layers. The period thickness, the total thickness of one Mo and one Si layer, was $\sim 6 \mathrm{~nm}$. The deposition run started on September 1, 2005 and ended on September 7, 2005. The deposition was made with no interruptions to the system and took 6 days. The overall thickness of the coating was aimed for $70 \mu \mathrm{m}$. To achieve that we had to perform 11,700 revolutions with velocities of about $2 \mathrm{rpm}$ (revolution per minute) over the Si target and $1.1 \mathrm{rpm}$ over the Mo target. An RGA scan was taken before and after the deposition run. Two cryopumps were on during the RGA scan before the deposition run but only one cyropump was on at the end of the run. This partly explains higher partial pressures after the run as seen in Figure 1. We estimate that about half of the Mo and half of the $\mathrm{Si} 1 / 4$ " thick targets were consumed during this experiment. Although both sources were running smoothly throughout the deposition run we found a substantial amount of flakes on the Mo sputtering source (Fig. 2).

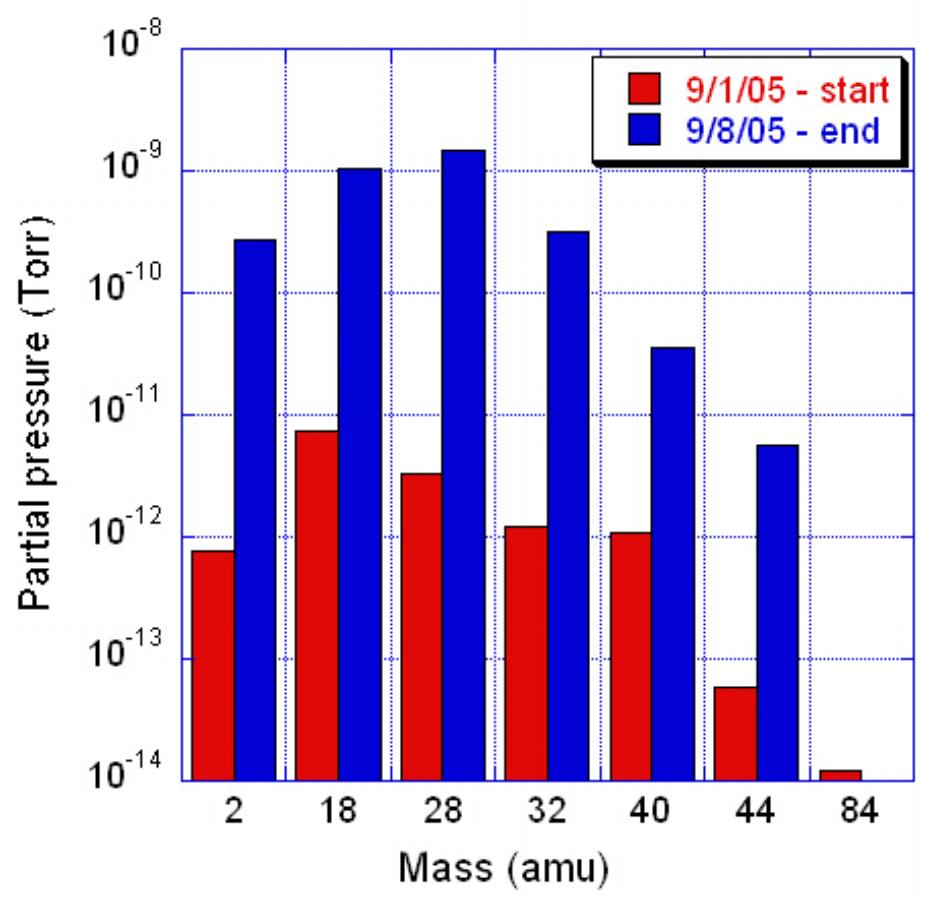

Figure 1: RGA scan before and after the deposition run. Mass $2\left(\mathrm{H}_{2}\right), 18\left(\mathrm{H}_{2} \mathrm{O}\right), 28(\mathrm{CO}), 32$ $\left(\mathrm{O}_{2}\right), 40(\mathrm{Ar}), 44\left(\mathrm{CO}_{2}\right)$, and 84 were detected. 


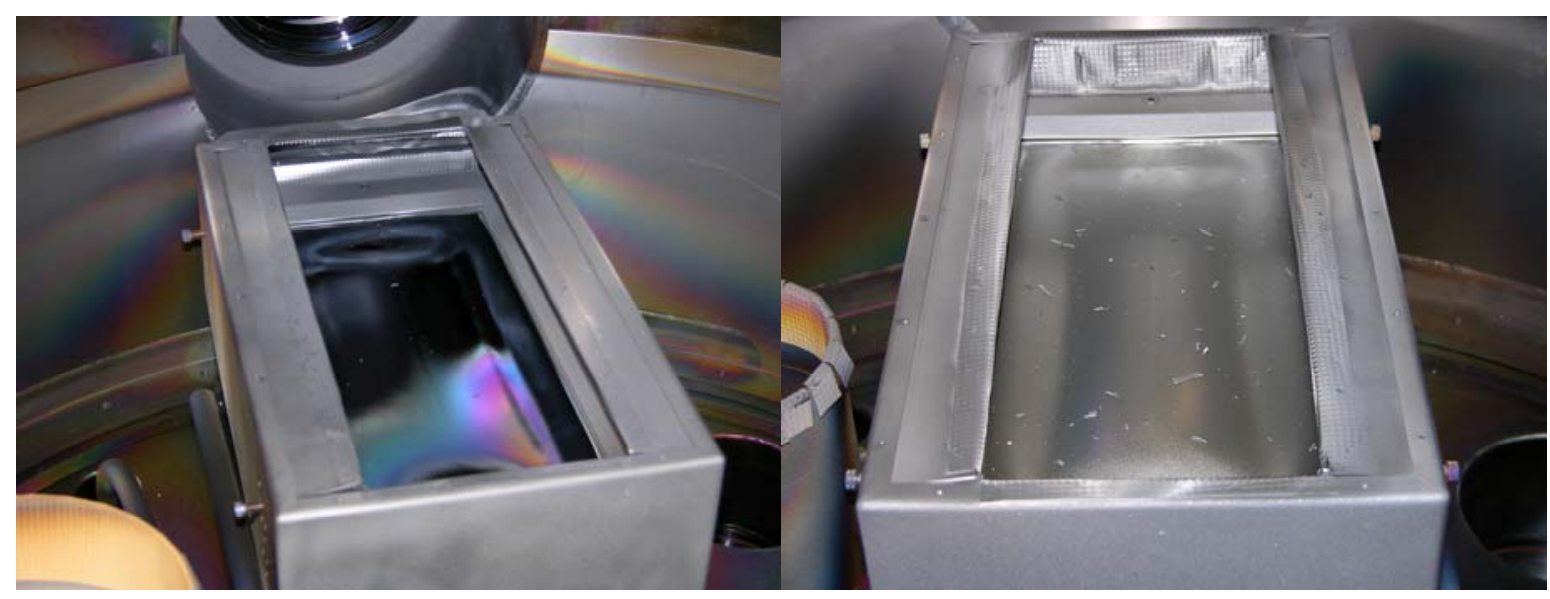

Figure 2: After the long deposition run the silicon sputtering target (left) has fewer flakes than the molybdenum sputtering target (right).

The $70 \mu \mathrm{m}$ thick coating had an excellent adhesion (no ripples or other signs of delamination) and looked smooth to the eye (Fig. 3).

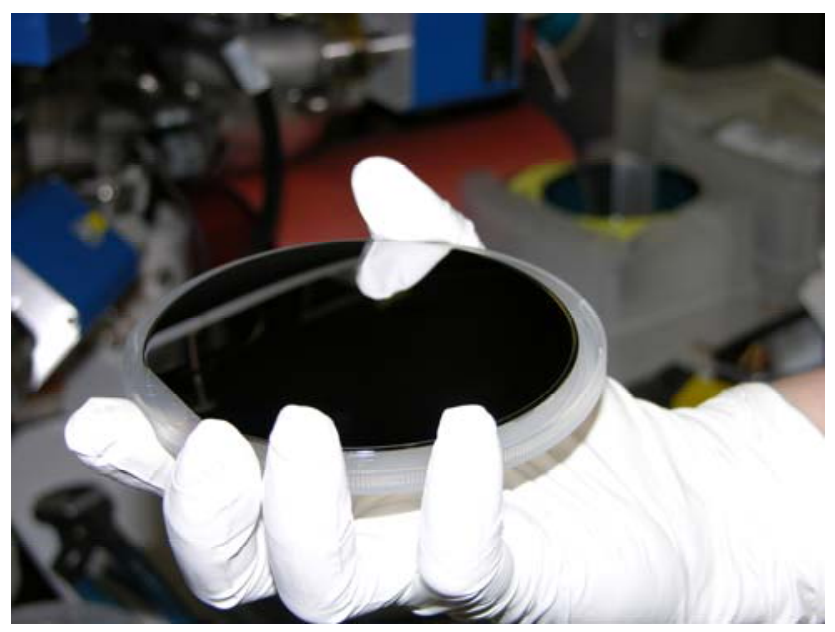

Figure 3: $70 \mu \mathrm{m}$ thick coating on the Si wafer substrate has excellent adhesion.

Analysis: Attempts to measure stress of the thick coating failed due to low laser intensity on Tencor FLX-2320 tool. This could be due to non-parabolic final shape of the wafer.

We performed $2 \times 2 \mu \mathrm{m}^{2}$ and $10 \times 10 \mu \mathrm{m}^{2}$ AFM measurements in multiple locations to determine the surface roughness of $70 \mu \mathrm{m}$ thick coating. The results show consistent surface roughness between $1.3-1.4 \mathrm{~nm}$ rms. A typical surface structure can be seen on Figure 4. In addition PSD spectrum is shown in Figure 5. Cross section SEM images show no columnar growth and no voids (Fig. 6). In fact, distinct layers are seen in the bottom, in the middle and on the top of this $\sim 70 \mu \mathrm{m}$ thick multilayer. 


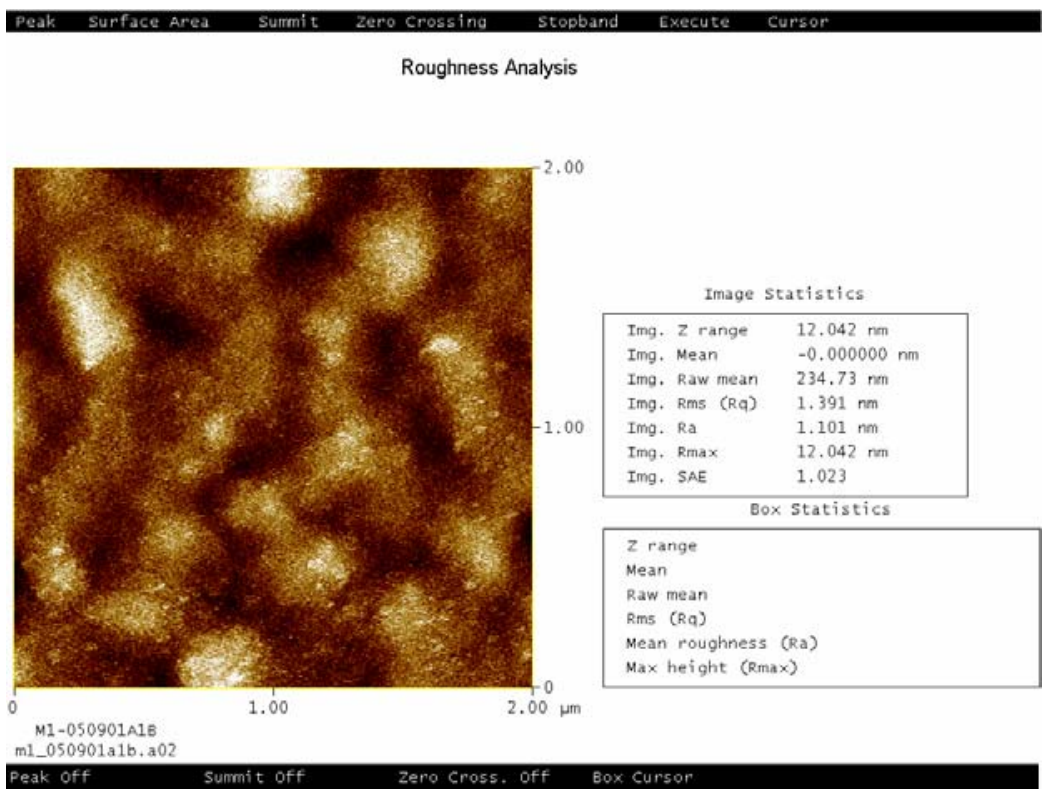

Figure 4: AFM surface map of 2 × $2 \mu \mathrm{m}^{2}$ area showing characteristic structure with $\sim 14 \mathrm{~nm} \mathrm{rms}$ roughness.

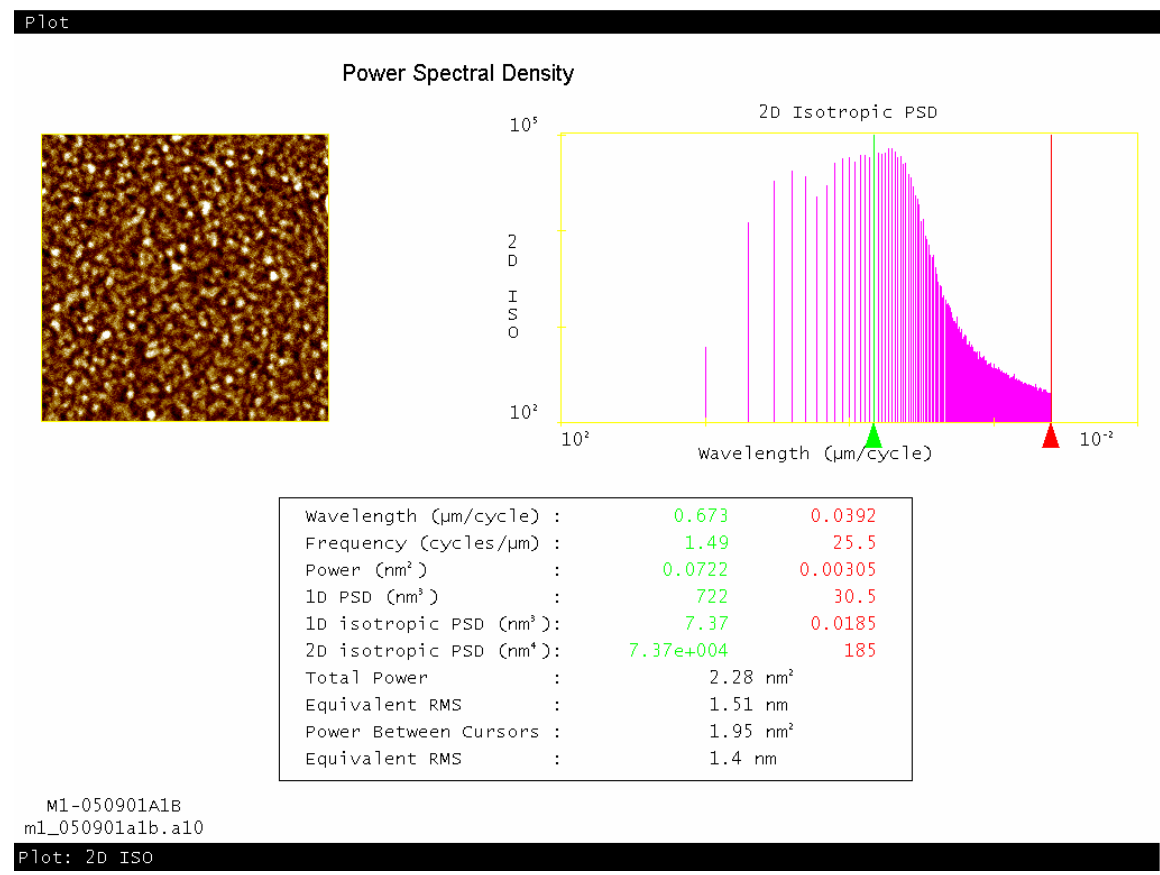

Figure 5: 2D isotropic power spectral density spectrum calculated from AFM 2 x $2 \mu \mathrm{m}^{2}$ map. 


\section{top}
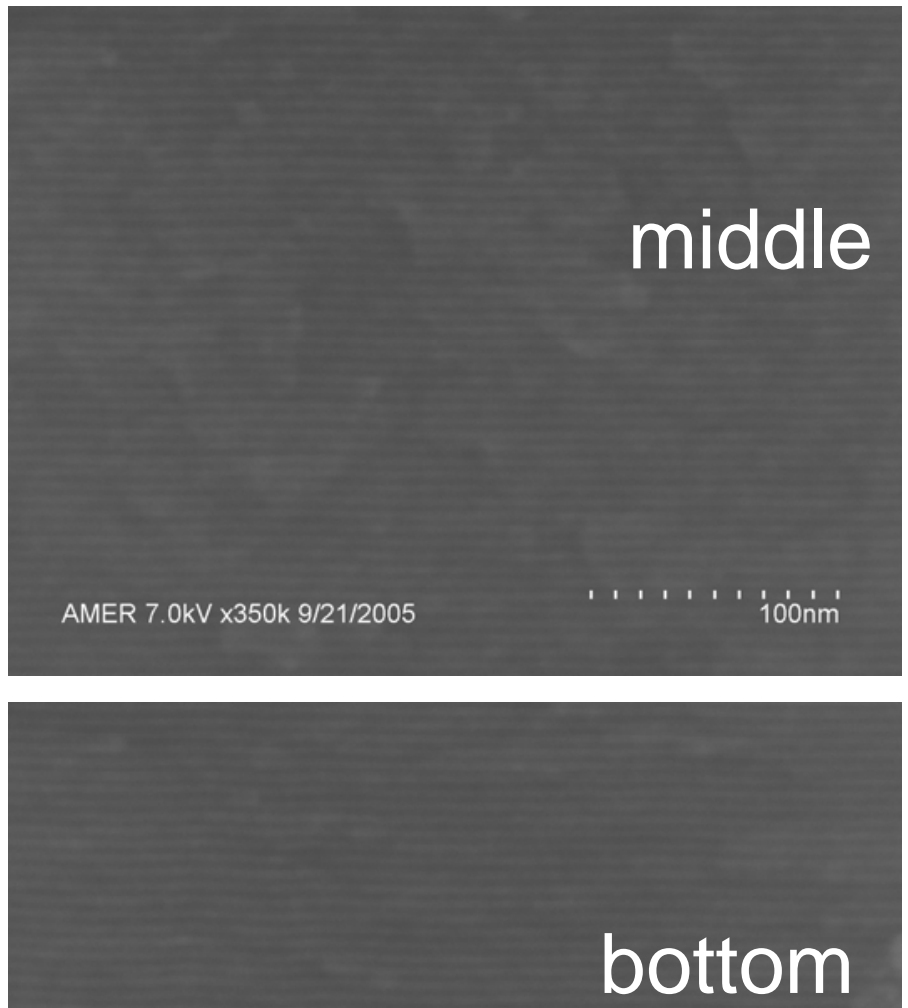

Figure 6: Cross section SEM images form the bottom, middle and top part of the multilayer show dense, smooth coating and no columnar growth. 

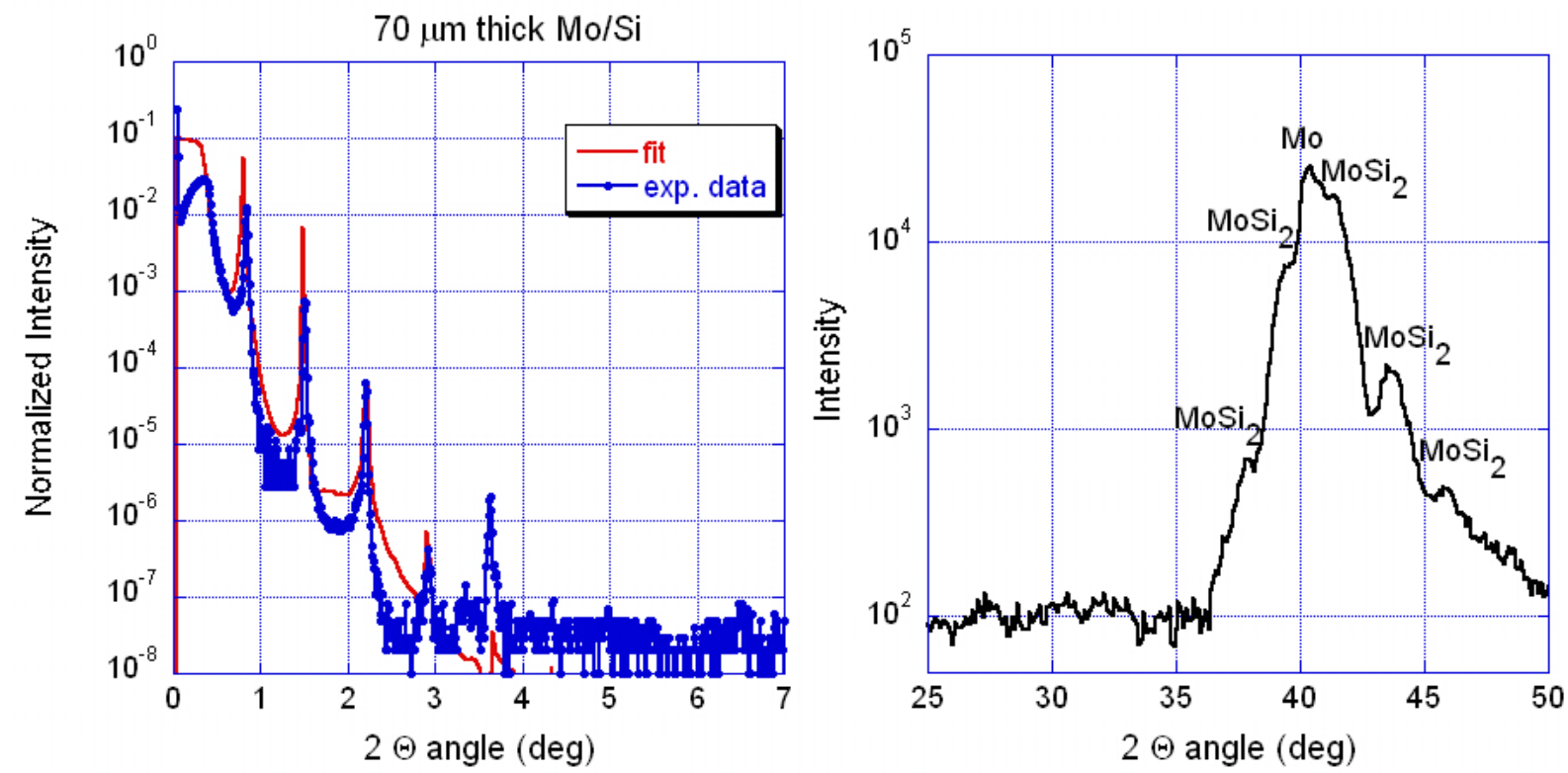

Figure 7: Grazing incidence x-ray diffraction spectrum (left) and high angle x-ray diffraction spectrum (right)

Sharp and well-resolved Bragg peaks, corresponding to Bragg reflections from the interfaces, are associated with the bilayer period and suggest that the multilayer structure is still very smooth, even on the top of $70 \mu \mathrm{m}$ thick multilayer stack (Fig.7, left). Since grazing incidence $\mathrm{x}$-ray diffraction samples over an area of several square millimeters it is an additional proof that the coating on the top is smooth. It is well known that Mo and $\mathrm{Si}$ form $\mathrm{MoSi}_{2}$ on the interfaces. Since this deposition run was very long and the substrate was not cooled, the substrate temperature could have reached over $120^{\circ} \mathrm{C}$. From our previous studies we know that this is sufficient to accelerate diffusion of Mo and $\mathrm{Si}$ and hence, the growth of $\mathrm{MoSi}_{2}$ inter-layers. It is, therefore, of no surprise to see evidence of $\mathrm{MoSi}_{2}$ in this coating. The high angle $\mathrm{x}$-ray diffraction spectrum (Fig. 7, right) suggests different crystalline orientations of $\mathrm{MoSi}_{2}$ with the most prominent being $\mathrm{MoSi}_{2}(111)$ at $41.603^{\circ}, \mathrm{MoSi}_{2}(110)$ at $39.744^{\circ}$ and $\mathrm{MoSi}_{2}(103)$ at $44.683^{\circ}$. These same peaks are also the most intense peaks diffracting from a powder sample. The peaks are relatively broad indicating small grain size in the growth direction (normal to the substrate surface). The polycrystalline Mo on the other hand has a $<110>$ texture in the growth direction. This produces a diffraction peak at $2 \theta_{<110>}=40 \mathrm{deg}$. We can model the profile of the diffraction peak as a Gaussian,

$$
I(2 \theta)=I_{0} \exp \left[-\frac{\left(2 \theta-2 \theta_{<110>}\right)^{2}}{2 \sigma^{2}}\right]
$$

Note that $2 \sigma$ is the width of the XRD peak in $2 \theta$ space, and so has units of radians. The thickness of the crystalline Mo layer is inversely proportional to the peak width according to ${ }^{2}$,

${ }^{2}$ W. H. Zachariasen, Theory of X-ray Diffraction in Crystals, (John Wiley \& Sons, New York, 1945) p. 102. 


$$
\tau_{M o}=\sqrt{\frac{2}{\pi}} \frac{\lambda}{2 \sigma \cos \theta_{<110>}}
$$

Here $\lambda$ is the $\mathrm{Cu}-\kappa \alpha$ x-ray wavelength of $0.1542 \mathrm{~nm}$. Using this method we estimate that the Mo grain size in the growth direction to be $\sim 22 \mathrm{~nm}$. This is much larger than the individual Mo layer thickness $(1.5 \mathrm{~nm})$. All hereby presented data indicate that the Mo crystal size in the growth direction should be much smaller. It is possible that the large grain size $(22 \mathrm{~nm})$ is an interference effect between the subsequent Mo layers. A detailed modeling is required to explain this phenomenon but it is beyond the scope of this work. 